\title{
Os Fungos e a Glicosilação de Proteínas
}

\section{Introdução}

Dentre as modificações pós-traducionais, a glicosilação de proteínas é a mais comumente observada, sendo um processo importante tanto funcionalmente quanto estruturalmente. A produção de glicoproteínas abrange, não somente o reino animal, mas também as plantas, fungos e bactérias, por esses possuírem em suas células um conjunto de enzimas, denominadas glicosidases e glicosiltransferases, responsáveis pelas reações de formação de glicoproteínas ${ }^{1}$.

A formação das glicoproteínas envolve uma variedade enorme de ligações carboidrato-peptídeo, que podem ser observadas ocorrendo naturalmente, desde os mais primitivos microrganismos até os organismos pluricelulares mais complexos. Isso demonstra que a glicosilação de proteínas, como processo póstraducional, desempenha papel biológico essencial à vida $^{2}$.

A grande maioria das proteínas secretadas e presentes nas membranas celulares passam pelo processo de glicosilação. Os oligossacarídeos, estruturas contendo diversos açúcares, são ligados covalentemente às proteínas por dois tipos básicos de ligações: as $\mathrm{N}$-glicosídicas e as O-glicosídicas. A estrutura dos oligossacarídeos pode variar de estruturas simples até estruturas muito complexas com vários tipos de resíduos de carboidrato ${ }^{3}$.

A glicobiologia é o ramo da ciência que se destina ao estudo estrutural, químico, sintético e funcional dos glicanos (carboidratos) e seus derivados. Os glicanos são componentes celulares importantes e diversificados, com a habilidade de unir-se tanto a proteínas, como também a lipídeos ${ }^{4}$. Podem ocorrer basicamente dois tipos de glicosilação de proteínas: a chamada N-glicosilação, que envolve glicanos de estruturas e quantidades variadas, ligadas a uma sequência Aspartato-X-Serina/Treonina e o O-glicosilação, em que os glicanos se ligam a Serina ou Treonina, em estruturas menos robustas ${ }^{1}$.

Os produtos da glicosilação são peças importantes e fundamentais em processos biológicos e patológicos, sendo que, mudanças estruturais nos glicanos têm demonstrado relação direta com sua função. Com o desenvolvimento da química, da glicobiologia e da biologia molecular, tornou-se possível o estudo das proteínas glicosiladas como possíveis fontes de novas terapias, utilizando estas moléculas no estudo e no desenvolvimento de novos fármacos ou como sítios de ação para outras substâncias ${ }^{5}$.

As glicoproteínas são objetos de estudo em várias áreas, envolvendo diferentes campos do conhecimento. Mostram-se uma importante fonte de novas terapias, nos projetos de desenvolvimento de novas drogas e no campo da descoberta de novas tecnologias. Muitas mudanças estruturais em glicoproteínas estão sendo vinculadas à ocorrência de doença, por isso, essas proteínas modificadas são vistas como possíveis novas fontes terapêuticas ou alvos terapêuticos ${ }^{6}$.

Alguns estudos têm demonstrado a relação entre erros na glicosilação e o câncer. Porém, não se sabe ao certo se o erro na glicosilação é a causa do 
aparecimento do tumor ou uma consequência dele. Algumas glicoproteínas relacionadas a tumores foram identificadas como possíveis alvos para inibidores tumorais e outras como antígenos imunogênicos importantes para o possível desenvolvimento de uma vacina eficiente contra o câncer. Existem também as que podem ser usadas como marcadores para diagnóstico e prognóstico de patologias ${ }^{7}$.

Além dos avanços relacionados ao câncer, a glicosilação e os glicanos vem desempenhando papel importante também no estudo do desenvolvimento de vacina contra o vírus da Imunodeficiência Adquirida (AIDS), na descoberta de novos antivirais, na pesquisa de novas terapias para desordens metabólicas e autoimunes, e ainda na elaboração de anticorpos monoclonais em vários contextos. $\mathrm{O}$ entendimento de processos patológicos e mecanismos de instalação de infecções por agentes infecciosos, envolvendo glicanos, também colabora para a descoberta de novas opções terapêuticas ${ }^{5}$.

O estudo da relação entre as estruturas dos glicanos e suas funções, assim como, o envolvimento da glicosilação em diagnóstico e prognóstico de doenças e os mecanismos moleculares envolvidos no desenvolvimento de patologias são temas de várias pesquisas nesta área. A análise estrutural detalhada das proteínas glicosiladas, principalmente das estudadas para fins terapêuticos e diagnósticos, é de grande importância, pois a estrutura da molécula pode afetar diretamente a imunogenicidade, a estabilidade e a farmacocinética da molécula ${ }^{6}$.

A caracterização de estrutural dos glicanos, devido a sua grande diversidade, é um processo complexo e dependente de várias técnicas. A espectrometria de massa e o uso de métodos cromatográficos têm demonstrado resultados satisfatórios no processo de caracterização dos glicanos ${ }^{1}$. O desenvolvimento tecnológico possibilitou que as técnicas de espectrometria de massa se tornassem cada vez mais específicas e sensíveis, possibilitando caracterização e identificação fidedignas ${ }^{8}$.

Justifica-searealização de estudos sobreaglicosilação de proteínas e glicanos como aprofundamento do conhecimento da relação estrutura-atividade e na busca de novas descobertas e possíveis novidades terapêuticas e biotecnológicas que futuramente poderão contribuir para o desenvolvimento de novos produtos para a saúde e importantes economicamente. O objetivo deste artigo é discorrer sobre glicoproteínas fúngicas e sua importância dentro da biotecnologia, assim como, as funções que desempenham no microrganismo produtor e possíveis utilidades.

\section{Utilização de Glicoproteínas Fúngicas}

Os fungos são organismos vivos, eucariotos e heterotróficos. Sua parede celular é rica em quitina e possuem a capacidade de armazenar glicogênio assim como as células animais. Estão inclusos em reino próprio denominado reino Fungi, e encontram-se dispersos nos mais diversos ecossistemas, contribuindo para diversos ciclos naturais, biológicos e ecológicos. Podem ser leveduriformes, com somente um núcleo, ou filamentosos, possuindo maior número de núcleos ${ }^{9}$.

Estes organismos vivos desempenham importantes papéis em atividades humanas sendo que, desde a antiguidade, sabe-se, por meio de relatos, que eles são utilizados, por exemplo, na produção de alimentos por meio dos processos de fermentação. A biotecnologia é o campo que produz bens e serviços e desenvolve produtos por meio da utilização de organismos vivos e de seus derivados, em benefício e melhoramento da qualidade de vida do ser humano. Os fungos desempenham papel biotecnológico muito importante como pode ser observado na descoberta do antibiótico penicilina e na tecnologia de alimentos ${ }^{10}$.

Além da indústria de alimentos, exercem grande importância na produção de bebidas alcoólicas, na indústria farmacêutica, na produção de enzimas de uso e interesse industrial, biodegradação e tratamento de efluentes. Na agricultura, desempenham importante papel no auxílio do crescimento vegetal e na defesa contra fitopatógenos, ou seja, são opções viáveis para o biocontrole. Essas funções são possíveis apenas porque os fungos são capazes de produzir substâncias diversas devido ao seu conteúdo enzimático ${ }^{11}$.

A célula eucariótica dos fungos possui o conjunto de enzimas necessárias para a produção de glicoproteínas pelo método pós-traducional da glicosilação. Essas 
glicoproteínas podem exercer variadas funções. São essenciais nesses microrganismos para estrutura da parede celular e da célula como um todo, auxiliando na integridade e crescimento, diferenciação e sinalização, nas interações com outros seres vivos ${ }^{12}$.

A presença de glicoproteínas na superfície celular de fungos é a responsável, juntamente com outras proteínas, pelo potencial patogênico do fungo. $\mathrm{O}$ desenvolvimento de micoses depende diretamente dessas estruturas. Elas permitem aderência aos tecidos do hospedeiro, invasão de tecidos, evasão à resposta imune, dentre outras ações patogênicas. A expressão destas moléculas está diretamente ligada às ferramentas genômicas desses fungos ${ }^{13}$.

O fungo Candida albicans possui uma parede celular rica em carboidratos isolados e carboidratos ligados a proteínas. Essas glicoproteínas têm importante papel antigênico ou alergênico quando é analisada a interação desse fungo leveduriforme com seus possíveis hospedeiros, principalmente o homem. A concentração dessas substâncias pode variar ainda entre diferentes cepas, dependendo da variabilidade genética e expressão gênica de cada uma, e também de suas variações bioquímicas ${ }^{14}$.

Outro fungo patogênico ao homem é o Paracoccidioides brasiliensis responsável por desenvolver uma patologia denominada paracoccidioidomicose. Estudo envolvendo a produção de anticorpos monoclonais contra a glicoproteína GP70 deste fungo demonstrou que esta molécula desempenha função importante na instalação da infecção, dando ao fungo a capacidade de escape ao sistema imunológico. A GP70 mostrou inibir a atividade fagocítica de macrófagos e também a liberação de substâncias importantes na destruição do patógeno ${ }^{15}$.

A paracoccidioidomicose é uma doença de grande importância em saúde pública no Brasil. As técnicas utilizadas para diagnóstico são baseadas na procura de antígenos, uma vez que os anticorpos são de difícil detecção. A própria GP70 tem sido procurada nas técnicas que avaliam a presença de antígeno. Além dela, a glicoproteína GP43, de grande importância para a patogênese do fungo também é o principal antígeno para o diagnóstico sorológico da infecção ${ }^{16}$.

Os fungos não causam patologias somente em seres humanos. Existem alguns tipos de fungos, chamados fitopatógenos, que são responsáveis por desenvolver patologias em plantas e, por isso, podem comprometer a produção agrícola e a produção de produtos para consumo humano. Um exemplo destes fungos é o Fusarium subglutinans. Para se desenvolver mecanismos que combatam esse fungo, é imprescindível conhecer sua estrutura e composição química. A parede celular desse fungo é composta por uma glicoproteína constituída por mais de $50 \%$ de proteínas e $30 \%$ de açúcares, com a manose sendo o constituinte glicídico principal ${ }^{17}$. Além do Fusarium subglutinans, existem diversas espécies de fungos fitopatógenos. Podemos destacar o Botrytis cinerea ${ }^{18,}$ Sclerotinia sclerotiorum ${ }^{19}$, Rhizoctonia solani e Fusarium solani ${ }^{20}$.

Para o combate a esses fitopatógenos, uma alternativa que visa à substituição da utilização de pesticidas é o uso de mecanismos de biocontrole. Um desses mecanismos muito estudado é a utilização de outros fungos que sejam antagonistas aos fitopatógenos e esses, podem até mesmo, favorecer o desenvolvimento dos vegetais. O Trichoderma harzianum é um fungo filamentoso que tem demonstrado papel importante no controle de fitopatógenos ${ }^{21}$. Estudos futuros visam demonstrar a produção de glicoproteínas por este fungo, a importância dessas substâncias e sua relação com o biocontrole de fitopatógenos.

Fungos leveduriformes também têm mostrado capacidade de combate a fitopatógenos por meio da produção de toxinas que possuem efeito inibitório sobre o crescimento das hifas e a germinação de esporos ${ }^{22}$. Muitas toxinas produzidas por estas leveduras têm estrutura glicoproteica e esta estrutura está relacionada intimamente com o mecanismo de ação destas substâncias frente a outros fungos ${ }^{23}$.

Certos fungos têm a capacidade de se associar simbioticamente a raízes de plantas, formando o que chamamos de micorrizas. Um grupo desses fungos é chamado de fungos micorrízicos arbusculares e são de grande importância na microbiota do solo e também para a agricultura ${ }^{24}$. Essa importância se deve principalmente à glomalina, uma glicoproteína que auxilia na fertilização do solo, permeabilidade da água e retenção de carbono e outras partículas. Pesquisas com a glomalina podem aprofundar conhecimento 
acerca da estrutura e qualidade dos solos, assim como, promover o desenvolvimento de novas tecnologias e produtos para agricultura ${ }^{25}$.

Os benefícios da presença de fungos micorrízicos no solo estão intimamente ligados à presença das glomalinas. Além da retenção de carbono e da permeabilidade da água, essa glicoproteína permite a formação de aglomerados de metais, que funcionam como agentes quelantes do solo. $\mathrm{O}$ teor de glomalina presente no solo pode indicar quão degradado ou saudável este solo está ${ }^{26}$.

A utilização biotecnológica de fungos e seus produtos tem se tornado cada vez mais ampla. Um exemplo disso é o uso de fungos basidiomicetos para limpeza de efluentes resultantes do processamento têxtil. Esses fungos possuem complexos enzimáticos responsáveis pela degradação de produtos químicos, principalmente corantes, que podem ser prejudiciais à natureza e aos seres vivos se permanecerem nos efluentes. Grande parte destes complexos possuem glicoproteínas, dentre elas, a lignina peroxidase, a manganês peroxidase, e a lacase. A biodegradação fúngica evita a utilização de produtos químicos para a limpeza dos efluentes o que diminui a concentração de compostos que podem alterar processos ambientais naturais ${ }^{27}$.

A indústria farmacêutica também é responsável por forte impacto ao meio ambiente, uma vez que contamina efluentes com produtos resultantes da produção de medicamentos em larga escala. A utilização de fungos para limpeza desses efluentes parece ser um produto biotecnológico de grande valor que diminui os impactos da produção de medicamentos sobre os ecossistemas. Fungos como o Pycnoporus sanguíneos e Trametes versicolor são produtores da glicoproteína lacase e poderão ser utilizados para tratamento de efluentes industriais diminuindo o impacto desta atividade sob a natureza ${ }^{28}$.

Fungos produtores de lacase, lignina peroxidase e manganês peroxidase também podem ser utilizados para degradação de matéria orgânica. O Trametes villosa é um desses fungos que apresentam grande potencial para degradação e remoção de substâncias húmicas em ambientes aquáticos. Demonstram ser uma biotecnologia melhor que as bactérias nesse sentido, pois crescem normalmente em meio ao estresse destes ambientes, ao contrário destes seres procariontes ${ }^{29}$.

Existe uma glicoproteína de grande importância industrial chamada tanase. Esta pode ser produzida por fungos e é utilizada em larga escala na produção industrial de produtos como cerveja, sucos de frutas e vinhos. Sua obtenção não biotecnológica é cara, por isso, os fungos seriam uma ótima alternativa para essa produção ${ }^{30}$. Podem-se produzir as tanases por fermentação, por meio, por exemplo, da utilização de fungos Aspergillus sp., tendo como substrato resíduos agroindustriais de diversos produtos, como laranja, uva e café, com produção satisfatória da glicoproteína ${ }^{31}$.

O uso de proteínas recombinantes, como moléculas ativas farmacologicamente, é cada vez mais comum. Grande parte dessas proteínas necessitam ser glicosiladas para exercerem sua função, por esta depender de sua estrutura. Por isso, não podem ser produzidas por células procariótica. Assim, as proteínas recombinantes glicosiladas são produzidas em células de mamíferos em laboratório. Os fungos têm sido estudados como sistemas de produção dessas glicoproteínas, como forma alternativa ao uso de células de mamíferos e têm demonstrado eficiência nessa síntese. Sua parede celular rígida confere aos fungos maior resistência ao estresse e maior facilidade de manipulação em laboratório ${ }^{32}$.

Algumas glicoproteínas produzidas por fungos já demonstraram possuir potencial farmacológico. O Aspergillus nidulans da linhagem RT2 é capaz de produzir uma glicoproteína chamada nandina que possui diferentes graus de glicosilação. Esta glicoproteína foi estudada e demonstrou-se in vitro e in vivo a sua atividade anti-inflamatória. Esta molécula inibe in vitro a produção da ciclooxigenase- 2 e in vivo mostrou atividade em dois modelos de inflamação diferentes ${ }^{33}$.

O fungo Scleroderma nitidum possui polissacarídeos que tiveram suas atividades farmacológicas avaliadas e demonstraram atividade anti-inflamatória e antioxidante. Ao analisarem-se as estruturas desses polissacarídeos em infravermelho, observou-se que eles provavelmente tenham estrutura glicosilada, formando um complexo polissacarídeo-proteína ${ }^{34}$.

\section{Considerações Finais}

De acordo com os relatos feitos nesta revisão, podese concluir que as glicoproteínas têm várias funções 
e são de grande importância para a biotecnologia e o desenvolvimento em vários campos. As glicoproteínas produzidas por fungos são importantes meios para se conhecer a estrutura do fungo e sua patogenicidade quando este é de causar doença no homem e em outros animais. São importantes no conhecimento da imunidade e no desenvolvimento de substâncias farmacologicamente ativas que algum dia poderão originar novos medicamentos.

A importância dos fungos na produção de produtos é conhecida desde os tempos mais remotos. A utilização da fermentação possibilitou que produtos hoje, amplamente consumidos, fossem introduzidos no mercado e melhorados com o passar dos anos. Muito do que é utilizado, proveniente desses microrganismos, surgiu graças a glicoproteínas produzidas por eles. Estas substâncias são utilizadas no processamento industrial e no tratamento de resíduos químicos em efluentes, o que é de grande importância para o meio ambiente.

Os fungos têm sido usados também como biocontrole de fitopatógenos, tendo enorme importância econômica na manutenção de grandes lavouras e evitam as perdas de produção por patologias que acometem as plantas. Além disso, são importantes componentes do solo, influenciando na fertilidade e composição, facilitando a permeabilidade da água, sendo importantes indicadores de degradação.

Diante destas conclusões, fica claro que estudos envolvendo a produção de glicoproteínas por fungos são importantes em várias áreas do conhecimento, podendo determinar o surgimento de novos produtos que poderão ser utilizados nos mais diferentes campos, englobando desde a área da saúde até a produção industrial.

\section{Referências}

1. Easton, R. Life Science. 2011, 48, 1.

2. Spiro, R.G. Glycobiology. 2002, 12, 43.

3. Voet, D.; Voet, J.G. Bioquímica. 4.ed. Artmed: São Paulo, 2013.

4. Ohtsubo, K.; Marth, J.D. Cell. 2006, 126, 855.

5. Dalziel, M.; Crispin, M.; Scanlan, C.N.; Zitzmann, N.; Dwek, R.A. Scien. 2014, 343, 37.

6. Marinõ, K.; Bones, J.; Kattla, J.J.; Rudd, P.M. Nat. Chem. Bio. 2010, 6, 713 .
7. Hakomori, S. PNAS. 2002, 99, 10231.

8. Stavenhagen, K.; Kolarich, D.; Wuhrer, M. Chrom, 2015, 78, 307.

9. Trabulsi, L.R.; Alterthum, F. Microbiologia. 3.ed. Atheneu: São Paulo, 2008.

10. Faleiro, F.G.; Andrade, R.S.M.; Júnior, F.B.R. Embrapa: Planaltina, 2011.

11. Abreu, J.A.S.; Rovida, A.F.S.; Pamphile, J.A. Revista Uningá. 2015, 21, 55 .

12. Pinto, M.R.; Barreto-Bergter, E.; Taborda, C.P. Braz. Jour. Micro. 2008, 39, 195.

13. Santos, R.S.; Lima, O.S.; Almeida, D.C.; Barbosa, M.S. Rev. Saú. Pesq. 2012, 5, 183.

14. Sippert, E.A.; Tartari, D.C.; Souza, J.H.; Silva, T.; Simão, R.C.G.; Gandra, R.F. Anais do XIX Encontro Anual de Iniciação Científica, Guarapuava-PR: Universidade Estadual do Oeste do Paraná, 2010.

15. Grosso, D.M. Tese. Universidade Federal de São Paulo (Unifesp). São Paulo, 2013.

16. Pereira, A.L.; Amorim, F.G.; Júnior, R.B.M. Rev. Elet. Farm. 2012, 9, 29.

17. Santos, D.W.; Ricardo, W. Cadernos da Escola de Saúde. 2010, 3,1 .

18. Lisboa, B.B.; Bochese, C.C.; Vargas, L.K.; Silveira, J.R.P; Radin, B.; Oliveira, A.M.R. Ciência rural. 2007, 37, 1255.

19. Ethur, L.Z.; Cembranel, C.Z.; Silva, A.C.F. Ciência Rural. 2001, 31,885 .

20. Pereira, J.L.; Queiroz, R.M.L; Charneau, S.O.; Félix, C.R.; Ricart, C.A.O; Silva, F.L.; Steindorff, A.S.; Ulhoa, C.J.; Noronha, E.F. Plos One. 2014, 9, 1.

21. Steindorff, A.S.; Ramada, M.H.S; Coelho, A.S.G.; Miller, R.N.G.; Júnior, G.J.P.; Ulhoa, C.J.; Noronha, E.F. BMC Genomics. 2014, 15, 1 .

22. Fazio, M.L.S. Tese. Universidade Estadual Paulista (UNESP). São José do Rio Preto, 2009.

23. Martinac, B.; Zhu, H.; Kubalski, A.; Zhou, X.; Culbertson, M.; Bussey, H.; Kung, C. Cell. Bio. 1990, 87, 6228.

24. Mergulhão, A.C.E.S. Tese. Universidade Federal de Pernambuco. Recife, 2006.

25. Rillig, M.C. Can. Jour. Soil. Scie. 2004, 84, 355.

26. Pereira, C.D.; Andrade, R.L.M.; Machado, C.T.T.; Malaquias, J.V.; Nascimento, A.; Lopes, V. In: FertBIo 2010, Guarapari-ES.

27. Souza, A.F.; Rosado, F.R. Revista em Agronegócios e Meio Ambiente. 2009, 2, 121.

28. Watanabe, R.A.M.; Júnior, H.M.O.; Sales, P.T.F.; Garcia, T.A.; Santiago, M.F. In: Congresso em pesquisa, ensino e extensão da UFG - CONPEEX, 3, 2006, Goiânia. 
29. Campos, R.F. Dissertação. Universidade Federal de Goiás. Goiânia, 2011.

30. Yao, J.; Guo, G.S.; Ren, G.H.; Liu, Y.H. Journal of Molecular Catalysis B: enzymatic. 2014, 101, 137.

31. Nascimento, K.B.M.; Martins, A.G.R,; Takaki, G.M.C.; Silva, C.A.A.; Okada, K. E-xacta. 2014, 7, 95.

32. Pourcq, K.; Schutter, K.; Callewaert, N. Appl. Micro. Biotech. 2010, 87, 1617.

33. Queiroz, J.C.F. Tese. Universidade de São Paulo (USP). São Paulo, 2007.

34. Nascimento, M.S. Dissertação. Universidade Federal do Rio Grande do Norte. Natal, 2010.

\section{Stéphanie Naoum* \& Valdirene N. Monteiro}

Ciências Exatas e Tecnológicas. Universidade Estadual de Goiás. Caixa Postal 459, CEP 75001-970, Anápolis, GO.

*E-mail: naoumstephanie@gmail.com 